\title{
Novel dopamine-modified cellulose acetate ultrafiltration membranes with improved separation and antifouling performances
}

\author{
Xi Ma ${ }^{1,2}$, Chengyang Wang ${ }^{3}$, Hanxiang Guo ${ }^{1,2}$, Zhaofeng Wang ${ }^{1,2}$, Nan Sun ${ }^{1,2}$, \\ Pengfei Huo ${ }^{1,2}$, Jiyou $\mathrm{Gu}^{1,2}$, and Yang $\mathrm{Liu}^{1,2, *}$ (i) \\ ${ }^{1}$ College of Material Science and Engineering, Northeast Forestry University, Harbin 150040, People's Republic of China \\ ${ }^{2}$ Key Laboratory of Bio-Based Materials Science \& Technology, Ministry of Education, Northeast Forestry University, Harbin 150040, \\ People's Republic of China \\ ${ }^{3}$ Key Laboratory of High Performance Plastics, Ministry of Education, College of Chemistry, Jilin University, Changchun 130012, \\ People's Republic of China
}

Received: 3 January 2022

Accepted: 14 February 2022

Published online:

8 March 2022

(C) The Author(s), under exclusive licence to Springer Science+Business Media, LLC, part of Springer Nature 2022

\begin{abstract}
Cellulose acetate (CA) is widely used in the preparation of ultrafiltration membranes due to its many excellent characteristics, especially chemical activity and biodegradability. To improve the inherent hydrophobic and antifouling properties of CA membrane, in this work, CA was successfully modified with dopamine (CA-2,3-DA) through selective oxidation and Schiff base reactions, which was confirmed by FTIR and ${ }^{1} \mathrm{H}$ NMR measurements. Then, CA-2,3-DA membrane with high water permeability and excellent antifouling property was prepared by the phase inversion method. Compared with the original CA membrane, the CA-2,3-DA membrane maintained a higher rejection ratio for BSA $(92.5 \%)$ with a greatly increased pure water flux $\left(167.3 \mathrm{~L} \mathrm{~m}^{-2} \mathrm{~h}^{-1}\right)$, which could overcome the trade-off between permeability and selectivity of the traditional CA membrane to a certain extent. According to static protein adsorption and three-cycle dynamic ultrafiltration experiments, the CA-2,3-DA membrane showed good antifouling performance and superior long-term performance stability, as supported by the experimental results, including flux recovery ratio, flux decline ratio, and filtration resistance. It is expected that this approach can greatly expand the high-value utilization of modified natural organic polysaccharides in separation engineering.
\end{abstract}

Handling Editor: Stephen Eichhorn.

Xi Ma and Chengyang Wang have contributed equally.

Address correspondence to E-mail: liuyang@nefu.edu.cn 


\section{Introduction}

Membrane separation technology consists of microfiltration (MF), ultrafiltration (UF), nanofiltration $(\mathrm{NF})$, reverse osmosis (RO), and membrane distillation (MD), with the characteristics of high separation efficiency, low energy consumption, and no pollution of the environment [1]. In the context of global water resource shortages and increasingly serious environmental problems, membrane separation technology has attracted widespread attention. Using such technology, the molecular weight cut-off of ultrafiltration membranes can be controlled between $10^{3}$ and $10^{6} \mathrm{Da}$, and the pore size can be adjusted in the range of 10-100 nm [2], which can effectively intercept proteins, viruses, dyes, and other macromolecules. In the current global COVID-19 outbreak, the unique advantages of ultrafiltration membranes are further highlighted. Due to its many advantages, ultrafiltration technology has been widely used in sewage treatment, oil-water separation, biomedicine, and the food industry. The membrane material is the main factor that determines the membrane performance. Currently, polymer materials, including cellulose and its derivatives [3], polysulfone [4], polyolefins, [5], and fluorinated materials [6] are most widely used in membrane separation. However, due to the inherent hydrophobic properties of these materials, they are easily contaminated during the ultrafiltration process.

Membrane fouling augments filtration resistance, and even clogs the membrane pores, thus reducing filtration efficiency, shortening the service life of the membrane, and greatly increasing the operating cost of membrane modules [7, 8]. To some extent, it hinders the application and development of membrane technology. To improve antifouling performance, various methods, such as additive blending [9], surface coating [10], and chemical modification [11, 12], have been studied. In addition to the above research strategies, dopamine, an exciting candidate material in the field of separation technology, is also increasingly considered [13]. Dopamine, a small molecule that contains both amine and catechol groups, is often used as an additive blended into the polymer matrix to improve the hydrophilicity of various membranes. Tian et al. prepared a polydopamine-modified $\mathrm{MoS}_{2}$ $\left(\mathrm{MoS}_{2} @ P D A\right)$ blended polyethersulfone ultrafiltration membrane. The membrane has excellent water permeability and selectivity; in particular, the rejection ratio of Janus Green B is as high as $99.88 \%$ [14]. $\mathrm{Mu}$ et al. modified hydroxyapatite nanotubes via bioinspired polydopamine and polyethylenemine codeposition(HANTs@PDA/PEI) and added them to a carboxylated polysulfone matrix to prepare ultrafiltration membrane. The results showed that the pure water flux of the hybrid membrane was about 3.2 times higher than that of the unfilled membrane, and the flux recovery ratio for BSA solution $\left(1 \mathrm{~g} \mathrm{~L}^{-1}\right)$ reached $90.8 \%$ [15]. Kallem et al. fabricated hybrid ultrafiltration membranes using different sulfonated functionalized polydopamine (SPDA) loading levels, with polyethersulfone as the polymer matrix, which significantly improved the antifouling performance of the membrane [16]. In some ways, although additive blending modification has significant advantages, there is generally no chemical bond between the additive and the polymer matrix, which makes it easy for modifiers to migrate, leading to deterioration of membrane selectivity and long-term stability.

Dopamine is of interest for modifying membrane surfaces because it provides a facile route to hydrophilization of (typically hydrophobic) membrane surfaces to improve the antifouling performance [17-20]. Choi et al. fabricated multifunctional coating materials with biofouling- and oil-foulingresistant and bactericidal properties using monomers containing mussel-inspired dopamine and plantbased cardanol groups [21]. Chen et al. used polydopamine to graft activated GO nanosheets onto ultrafiltration membranes to enhance their antifouling properties [22]. Li et al. reported a method for modifying mussel-inspired polyvinylidene fluoride (PVDF) membranes by inkjet printing with dopamine and then exposure to UV light irradiation. The optimized membrane (DA80-60/PVDF) exhibited superior oil/water separation efficiency and antifouling performance, and the oil rejection ratio was more than 99\% [23]. The above surface modification methods have a significant effect on improving membrane performance in a short time [24]. However, due to the self-polymerization and migration of dopamine in the process of modification and use, it agglomerates on the membrane surface, thus leading to the blockage of membrane pores. At the same time, the surface modification method has poor repeatability, and it is difficult to achieve large-scale industrial production. Therefore, there is an urgent need 
for a membrane material that not only has long-term stable separation and antifouling performance but also can realize continuous large-scale production.

Cellulose is a natural polymer with large reserves in nature. The hydroxyl group in the molecule has strong reactivity and easily undergoes chemical modification, such as esterification [25] and amidation [26], to prepare cellulose derivatives for different applications. Among them, cellulose acetate (CA), obtained by the acetylation part of the hydroxyl group on cellulose, is a promising membrane material with good pore-forming performance, high selectivity, and large water flux [27]. In addition, because cellulose acetate is the product of incomplete esterification and contains many active sites, it allows room for further modification. Given the advantages of cellulose acetate and dopamine, this paper reports a novel material comprising CA successfully modified with dopamine (CA-2,3-DA) through selective oxidation and Schiff base reactions. Then, CA-2,3-DA and $\mathrm{CA}$ were used as raw materials to prepare ultrafiltration membranes, with the CA membrane acting as the control.

\section{Experimental part}

\section{Materials}

Cellulose acetate (CA, $39 \mathrm{wt} \%$ acetyl), dopamine hydrochloride (97\%), polyvinylpyrrolidone (PVP $30 \mathrm{~K})$, and sodium periodate (98\%) were all supplied by Aladdin Reagent, China. Calcium chloride (99\%), sodium borohydride ( $98 \%$ ), and $N, N$-dimethyl acetamide (DMAc) were purchased from Beijing Chemical Reagent, China. Bovine serum albumin (BSA) and phosphate-buffered saline (PBS, $0.1 \mathrm{~mol} / \mathrm{L}, \mathrm{pH} 7.4$ ) were used as received from Dingguo Biotechnology Co. Ltd., China. All reagents were of analytical grade and used without further purification.

\section{Preparation of dopamine-modified cellulose acetate (CA-2,3-DA)}

The preparation of dopamine-modified cellulose acetate involves two steps: selective oxidation and Schiff base reactions. The specific process is shown in Scheme 1.

Dialdehyde acetate cellulose (DAC): Under nitrogen atmosphere and light-proof conditions, $15 \mathrm{~g}$ of cellulose acetate and $300 \mathrm{~mL}$ of distilled water were added to a three-necked $500 \mathrm{~mL}$ flask. Then, $15 \mathrm{~g}$ of sodium periodate and $22.5 \mathrm{~g}$ of calcium chloride were added to the system and stirred at $45^{\circ} \mathrm{C}$. After $6 \mathrm{~h}, 75 \mathrm{~mL}$ of glycol was added to react with excess sodium periodate in the system. After the reaction was complete (about $0.5 \mathrm{~h}$ ), the sublayer precipitation was separated and cleaned repeatedly with deionized water. Finally, vacuum drying was performed.

CA-2,3-DA: In a three-necked $100 \mathrm{~mL}$ flask, $3.0 \mathrm{~g}$ of DAC was dissolved in $30 \mathrm{~mL}$ of DMAc. Then, $1.0 \mathrm{~g}$ of dopamine hydrochloride was slowly added to the solution, which reacted for $12 \mathrm{~h}$ at $50{ }^{\circ} \mathrm{C}$. Then, $0.45 \mathrm{~g}$ of sodium borohydride was added to the system to continue the reaction for $3 \mathrm{~h}$. After the reaction, the products were washed thoroughly in deionized water and ethanol successively. Finally, they were dried in a vacuum drying oven for later use.

\section{Preparation of ultrafiltration membrane}

The polymer (CA or CA-2,3-DA, $15 \mathrm{wt} \%$ ) and poreforming agent PVP ( $3 \mathrm{wt} \%$ ) were dissolved in DMAc (82 $\mathrm{wt} \%$ ) to prepare the casting solution. When there were no bubbles in the system, a casting knife with a thickness of approximately $200 \mu \mathrm{m}$ was used to spread the casting solution evenly on a clean glass plate. To evaporate the solvent, it was left in the air for a period of time, then transferred to deionized water to allow the solvent, pore-forming agent, and non-solvent to diffuse in both directions. Two prepared membranes were washed several times with deionized water to remove the residual solvent and water-soluble pore-former and stored in fresh deionized water before use.

\section{Characterization}

The chemical structure changes of CA before and after modification were analyzed by FTIR-ATR (Bruker Vertex $80 \mathrm{~V}$ ) and ${ }^{1} \mathrm{H}$ NMR (Bruker 510 spectrometer) using DMSO- $\mathrm{d}_{6}$ as solvent. TGA (Perkin-Elmer Pyris 1) was used to test the thermal stability of CA and CA-2,3-DA in a nitrogen atmosphere, with a heating rate of $10{ }^{\circ} \mathrm{C} \mathrm{min}^{-1}$. SEM (JEOL JSM-7500F) was used to characterize the surface and cross-section morphology of the ultrafiltration membrane. Sample sections were obtained by the liquid nitrogen freezing fracture method, and gold spraying was performed before imaging. 
Scheme 1 Preparation route of CA-2,3-DA.

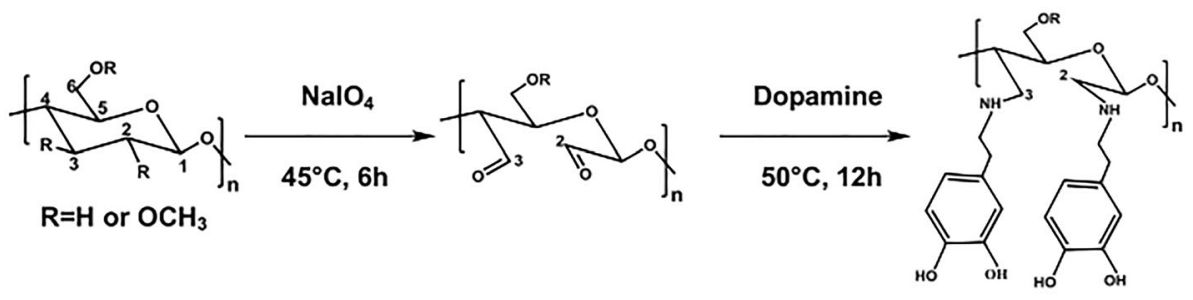

The static water contact angle (WCA) of samples was measured using a contact angle goniometer (KRUSS GMBH, Hamburg 100). Each sample was tested more than 5 times. Using the WCA data, the surface free energy can be calculated by the following formula:

$\cos \theta=-1+2 \sqrt{\frac{\gamma_{s}}{\gamma_{l}}} e^{-\beta\left(\gamma_{s}-\gamma_{l}\right)^{2}}$

where $\beta$ is a constant with a value of $0.0001247, \theta$ is the contact angle, $\gamma_{1}$ is the surface free energy of the liquid, and $\gamma_{s}$ is the surface free energy of the membrane.

By weighing the mass of the membrane in both dry and wet conditions, the total porosity of the membrane is calculated according to the following formula [28, 29]:

$\varepsilon=\frac{m_{w}-m_{d}}{\rho_{w} A l}$

where $m_{\mathrm{w}}$ and $m_{\mathrm{d}}$ are the weight of wet and dry membrane $(\mathrm{g})$, respectively; $A$ and $l$ are the area $\left(\mathrm{cm}^{2}\right)$ and thickness $(\mu \mathrm{m})$ of the membrane, respectively; and $\rho_{\mathrm{w}}$ is the density of pure water $\left(\mathrm{g} \mathrm{cm}^{-3}\right)$.

The mean pore diameter of the membranes was calculated by the Guerout-Elford-Ferry equation $[28,29]$ :

$r_{m}=\sqrt{\frac{(2.9-1.75 \varepsilon) \times 8 \eta l Q_{t}}{\varepsilon \times A \times \Delta P}}$

where $\eta$ is the viscosity of water $\left(8.9 \times 10^{-4} \mathrm{~Pa} \mathrm{~s}\right)$, $A$ is the membrane area $\left(\mathrm{cm}^{2}\right), Q_{\mathrm{t}}$ is the penetration rate of pure water $\left(\mathrm{m}^{3} \mathrm{~s}^{-1}\right)$, and $\Delta P$ is the operation pressure $(0.1 \mathrm{MPa})$.

\section{Performance test of ultrafiltration membrane}

\section{Static protein adsorption property tests}

First, ultrafiltration membrane of a certain size was immersed in phosphate-buffered saline (PBS, $0.1 \mathrm{M}$, $\mathrm{pH}=7.4)$, and sonication $(200 \mathrm{~W}, \mathrm{KQ5200B})$ was performed for $10 \mathrm{~min}$. Then, the ultrafiltration membrane was immersed in BSA-PBS solution (1.0 g $\mathrm{L}^{-1}$ ) for $24 \mathrm{~h}$ for the adsorption test. At the end of the adsorption process, according to the Lambert-Beer law, the concentration of BSA-PBS solution was measured with a UV-vis spectrophotometer (UV3600, Shimadzu) to obtain the total adsorption amount of BSA on the membrane.

\section{Dynamic separation performance tests}

A three-cycle dynamic ultrafiltration experiment was performed in a dead-end filtration apparatus to study the separation and antifouling performance of CA and CA-2,3-DA membranes. To obtain stable permeation flux, each membrane was pressurized with deionized water at $0.15 \mathrm{MPa}$ for $30 \mathrm{~min}$. Subsequently, the ultrafiltration operation was conducted for $1 \mathrm{~h}$ with pure water as the feed solution at a pressure of $0.1 \mathrm{MPa}$. During this period, the quality of filtrate was measured every $5 \mathrm{~min}$ and the pure water flux $\left(J_{\mathrm{w}}, \mathrm{L} \mathrm{m} \mathrm{m}^{-2} \mathrm{~h}^{-1}\right)$ of the membrane was calculated according to the following formula:

$J=\frac{V}{A t}$

where $V$ represents the penetration volume (L), $A$ represents the effective filtration area $\left(\mathrm{m}^{2}\right)$, and $t$ represents the penetration time (h). Subsequently, the BSA-PBS solution was used as the feed solution, and the ultrafiltration process was conducted for $1 \mathrm{~h}$ at $0.1 \mathrm{MPa}$. During this period, the water flux of the protein solution $\left(J_{\mathrm{P}}, \mathrm{L} \mathrm{m}^{-2} \mathrm{~h}^{-1}\right)$ was recorded every $5 \mathrm{~min}$. Meanwhile, the protein rejection ratio $(R)$ of the ultrafiltration membrane was calculated by the following formula:

$R(\%)=\left(1-\frac{C_{p}}{C_{f}}\right) \times 100 \%$

In the formula, $C_{\mathrm{P}}$ and $C_{\mathrm{f}}$ are the concentrations of permeate and feed solutions, respectively, which can be measured by UV-vis spectrophotometry. It should be noted that when the pure water flux of the 
membrane is measured again, the membrane needs to be thoroughly cleaned with deionized water. To evaluate the antifouling property of membranes, the flux recovery ratio $(F R R)$, total flux decline ratio $\left(R_{\mathrm{t}}\right)$, reversible flux decline ratio $\left(R_{\mathrm{r}}\right)$, and irreversible flux decline ratio $\left(R_{\mathrm{ir}}\right)$ were introduced, which are calculated by the following equations [29, 30]:

$\operatorname{FRR}(\%)=\left(\frac{J_{w, i}}{J_{w, i-1}}\right) \times 100$

$R_{t}(\%)=\left(\frac{J_{w, i-1}-J_{p, i}}{J_{w, i-1}}\right) \times 100$

$R_{r}(\%)=\left(\frac{J_{w, i}-J_{p, i}}{J_{w, i-1}}\right) \times 100$

$R_{i r}(\%)=\left(\frac{J_{w, i-1}-J_{w, i}}{J_{w, i-1}}\right) \times 100=R_{t}-R_{r}$

Darcy's law, the basic formula describing fluid flow through porous media, can be used to explain the relationship between membrane flux and fouling characteristics. The calculation equations are as follows $[29,30]$ :

$R_{t}=R_{m}+R_{f}=R_{m}+R_{c}+R_{p}=\frac{\Delta P}{\eta \times J_{p, i}}$

$R_{m}=\frac{\Delta P}{\eta \times J_{w, i-1}}$

$R_{m}+R_{p}=\frac{\Delta P}{\eta \times J_{w, i}}$

where $R_{\mathrm{t}}, R_{\mathrm{m}}$, and $R_{\mathrm{f}}$ are total hydraulic resistance, membrane resistance, and fouling resistance, respectively. $R_{\mathrm{f}}$ can be divided into $R_{\mathrm{p}}$ and $R_{\mathrm{c}}$, which represent the pore blocking resistance in the membrane and outer cake layer resistance on the membrane surface. The former is due to irreversible fouling, and the latter is related to reversible fouling [31].

\section{Results and discussion}

\section{Chemical structures of CA and CA-2,3-AD}

To have a clear understanding of the chemical structures of the prepared novel materials, FTIR was first used to characterize CA, DAC, and CA-2,3-DA. As shown in Fig. 1, 2 characteristic absorption peaks were found at $1739 \mathrm{~cm}^{-1}$ ( $\mathrm{C}=\mathrm{O}$ stretching vibration) and $1221 \mathrm{~cm}^{-1}$ (C-O stretching vibration), which should belong to the ester group of cellulose acetate
[32], so these absorption peaks existed in CA, DAC, and CA-DA. In addition, as an intermediate product, DAC had an absorption peak belonging to the hemiacetal bond formed between the aldehyde group and its adjacent hydroxyl group at $775 \mathrm{~cm}^{-1}$ [33], indicating that it was successfully prepared. In the spectra of CA-2,3-DA, 2 characteristic peaks of the benzene ring appeared at 1517 and $815 \mathrm{~cm}^{-1}$ attributed to out-of-plane deformation vibration of $\mathrm{C}-\mathrm{H}$ bond [34, 35]. This result indicated that dopamine was successfully modified to CA.

To further verify their chemical structures, $C A$ and CA-2,3-DA were characterized by ${ }^{1} \mathrm{H}$ NMR measurement. As shown in Fig. 2, compared with CA, the spectra of CA-2,3-DA generated some new peaks at 7.10 and $2.53 \mathrm{ppm}$, which were the characteristic triplet peaks of the benzene ring and the methylene peak in the dopamine structure, respectively $[36,37]$. Combining FTIR and ${ }^{1} \mathrm{H}$ NMR characterization, it was confirmed that CA was successfully modified by dopamine.

Figure 3 shows the TGA curves of CA and CA-2,3$\mathrm{DA}$ in a nitrogen atmosphere with a heating rate of $10{ }^{\circ} \mathrm{C} \mathrm{min}{ }^{-1}$. Compared with $\mathrm{CA}$, the thermal decomposition temperature of CA-2,3-DA was significantly lower, which might be due to the degradation of polymer backbones caused by selective oxidation and decomposition of the side groups. Although the thermal decomposition temperature of CA-2,3-DA decreased, it was still higher than $200{ }^{\circ} \mathrm{C}$, which could also meet the thermal stability requirement of ultrafiltration operation.

\section{Characterizations of ultrafiltration membranes}

To compare the microstructures of the two types of ultrafiltration membranes, SEM was used to characterize their surface and cross-section morphologies (Fig. 4). On the whole, both CA and CA-2,3-DA membranes showed the typical characteristics of an asymmetric microstructure, with a dense surface layer and finger-like pore sublayer. Compared with the CA membrane, the CA-2,3-DA membrane had a larger average pore size and porosity (Table 1), and many small pores were formed on its pore walls, which are favorable for increasing permeability. In addition, the CA-2,3-DA membrane had a smoother surface, which could effectively reduce the adhesion and adsorption of pollutants. This result might be 
Figure 1 FTIR spectra of CA, DAC, and CA-2,3-DA.
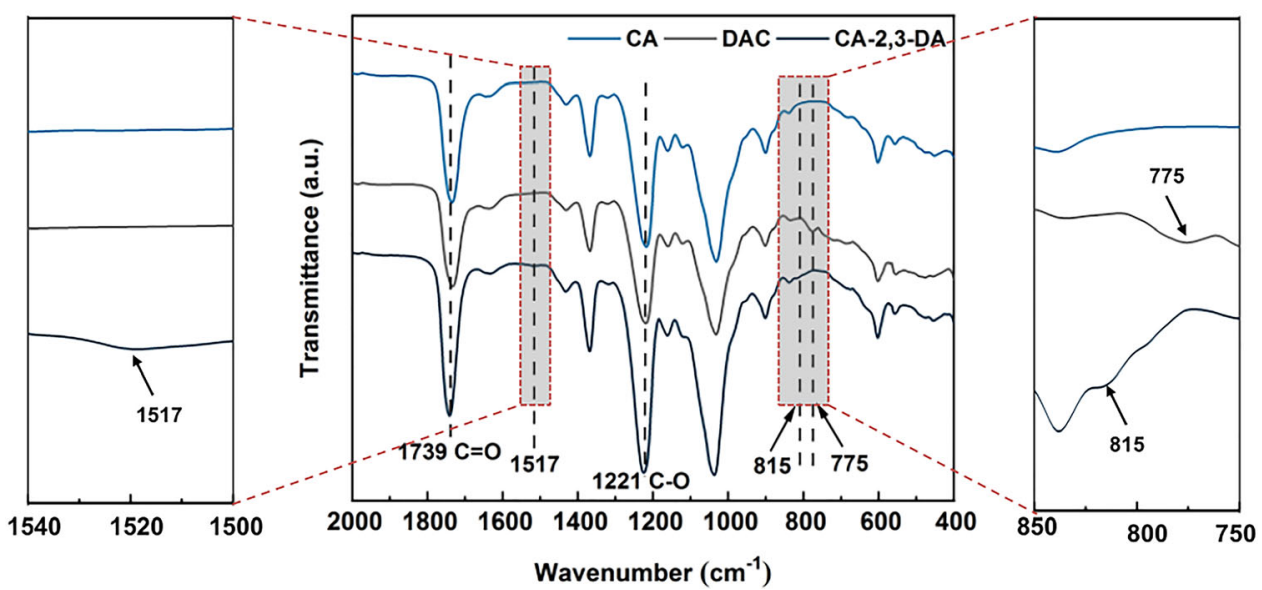

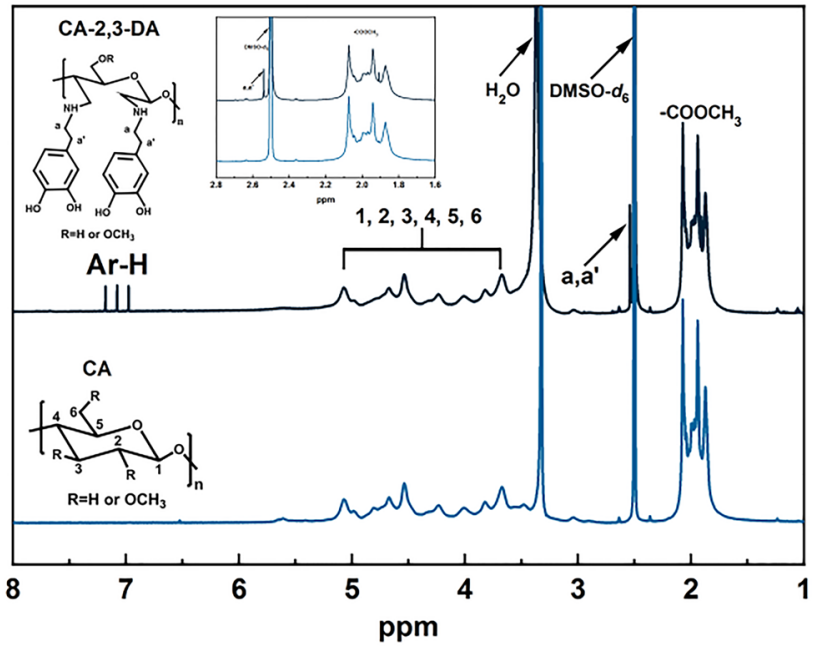

attributed to the introduction of hydrophilic dopamine accelerating the phase inversion rate during the membrane preparation process.

Hydrophilicity is an important index to measure the permeability and antifouling performance of membrane materials. The water contact angle is one of the most common and reliable techniques used to characterize the hydrophilicity of solid surfaces. Table 1 shows the water contact angles and surface energies of CA and CA-2,3-DA membranes. Compared with the original $\mathrm{CA}$ membrane $\left(69.8^{\circ}\right)$, the water contact angle of the CA-2,3-DA membrane decreased to $54.1^{\circ}$, which can be attributed to the introduction of hydrophilic dopamine.

Figure $2{ }^{1} \mathrm{H}$ NMR spectra of CA and CA-2,3-DA.
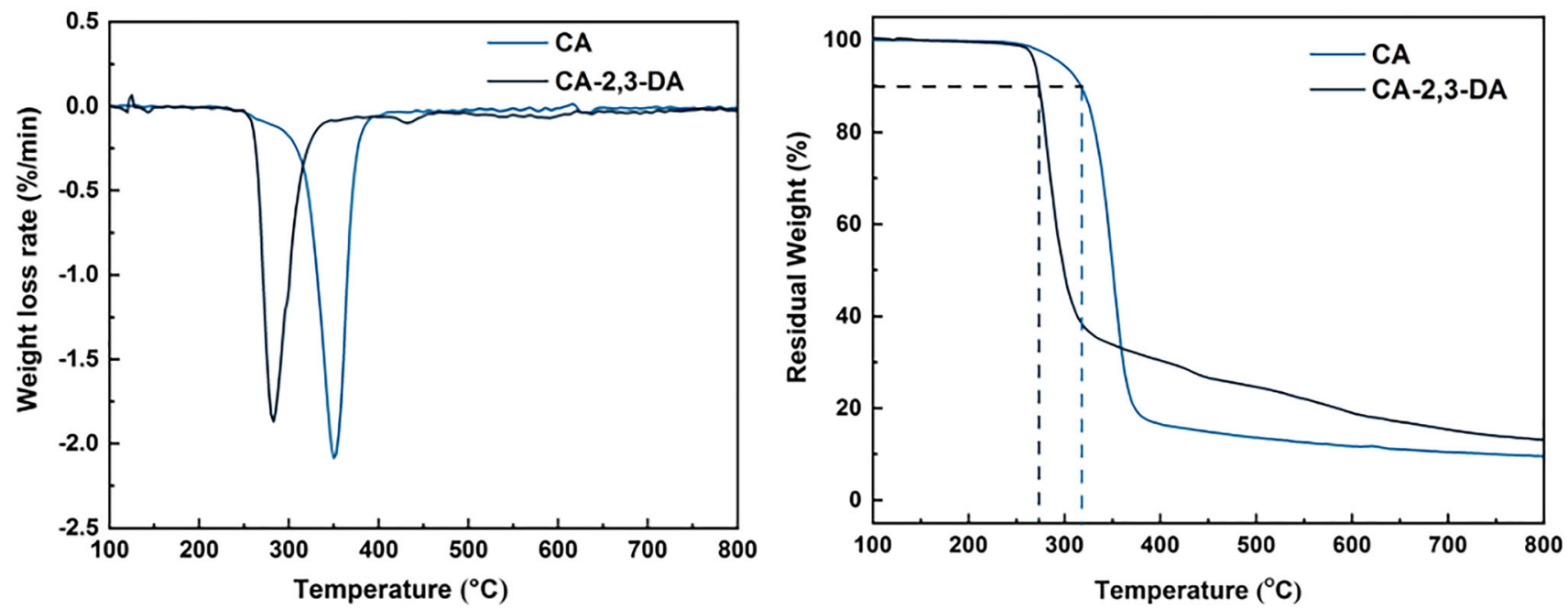

Figure 3 TGA/DTG curves of CA and CA-2,3-DA. 
Figure 4 SEM images of the a CA and b CA-2,3-DA membranes: (1) the overall cross-section morphology (magnification:300 $\times$ ), $(2)$ the partial cross-section morphology (magnification: $1000 \times$ ) and (3) the surface morphology (magnification: $1000 \times)$.
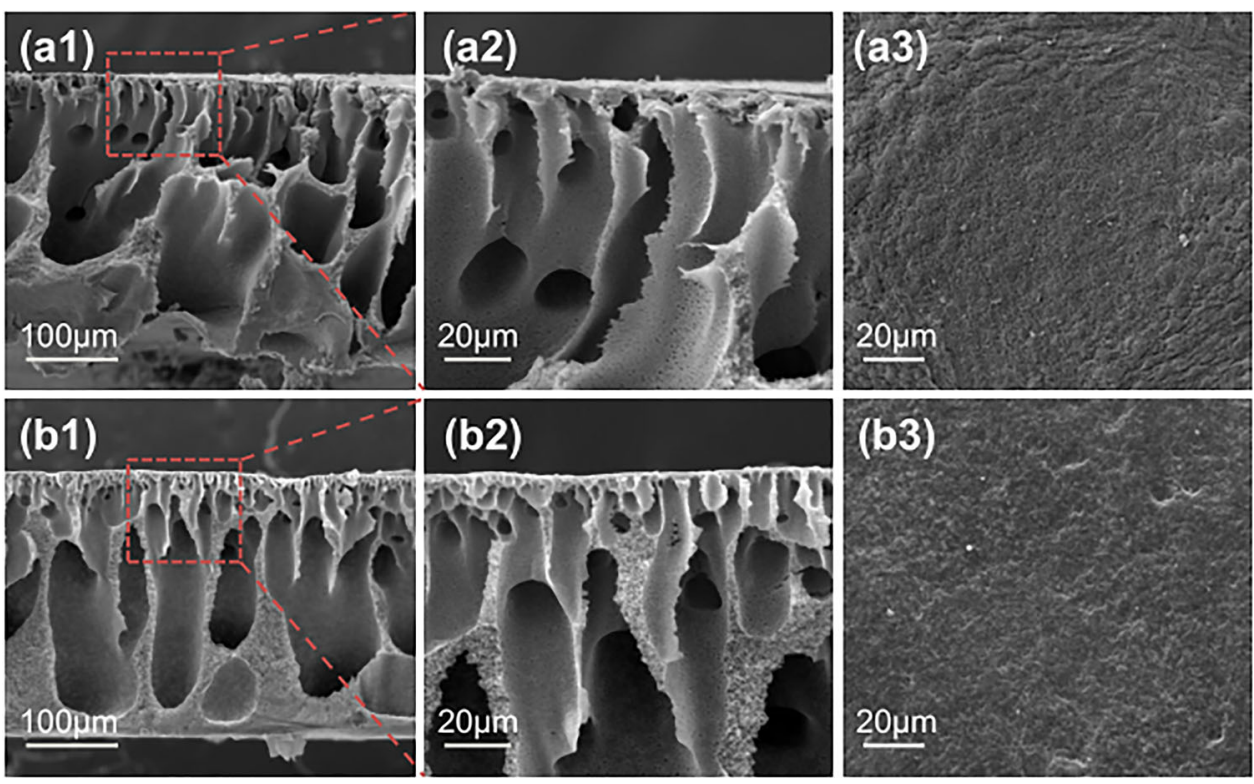

Table 1 Pore statistics, contact angles, surface energies, and BSA adsorption amounts of CA and CA-2,3-DA membranes

\begin{tabular}{|c|c|c|c|c|c|}
\hline Membrane & Porosity $(\%)$ & Mean pore size $(\mathrm{nm})$ & Contact angle $\left({ }^{\circ}\right)$ & Surface energy $\left(\mathrm{mJ} \mathrm{m}^{-2}\right)$ & BSA adsorption amount $\left(\mu \mathrm{g} \mathrm{cm}^{-2}\right)$ \\
\hline $\mathrm{CA}$ & $69.3 \pm 3.4$ & $21.7 \pm 1.5$ & $69.8 \pm 5.2$ & $41.8 \pm 3.3$ & $41.4 \pm 5.1$ \\
\hline CA-2,3-DA & $71.9 \pm 4.3$ & $28.3 \pm 1.1$ & $54.1 \pm 4.7$ & $47.5 \pm 3.1$ & $21.5 \pm 4.5$ \\
\hline
\end{tabular}

\section{Static protein adsorptions of ultrafiltration membranes}

The static antifouling performance of the ultrafiltration membrane was measured according to the amount of protein adsorption per unit area on the membrane surface. BSA was used as a model pollutant to measure protein adsorption, and the experimental results are summarized in Table 1 . The results show that the protein adsorption amount of the CA membrane was $41.4 \mu \mathrm{g} \mathrm{cm}{ }^{-2}$, while that of the CA2,3-DA membrane was significantly reduced to only $21.5 \mu \mathrm{g} \mathrm{cm}^{-2}$. Due to the lack of polar interaction between the CA membrane and water molecules, the hydrophobic interaction is the main contributing factor between the membrane and protein molecules, resulting in a large amount of BSA adsorbed on the surface of the membrane. However, there was less BSA adsorption on the CA-2,3-DA membrane, because the introduced dopamine can bind to water molecules and form a hydration layer on the membrane surface, thereby hindering the adsorption of proteins [38].

\section{Separation performances of ultrafiltration membranes}

The separation performance of ultrafiltration membrane is mainly reflected in two aspects, pure water flux and rejection ratio. Figure 5 illustrates the experimental results of CA and CA-2,3-DA membranes with distilled water and BSA as feed

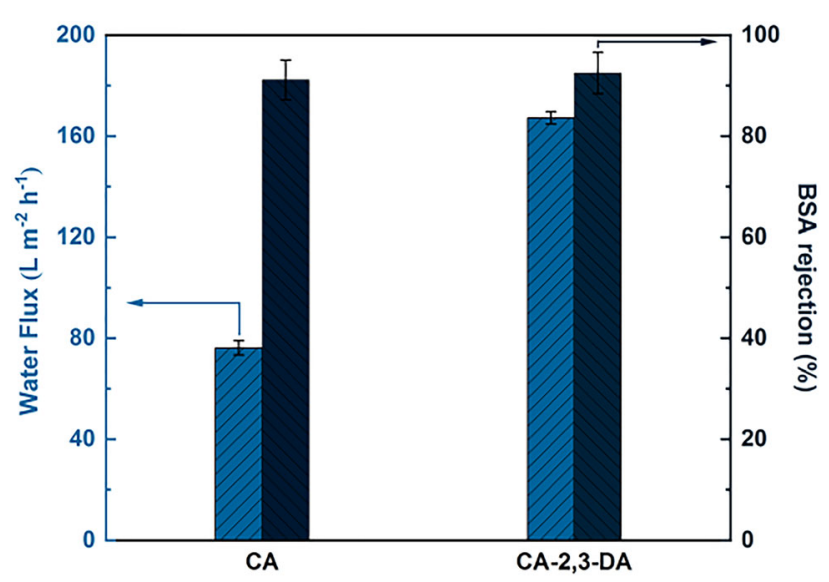

Figure 5 Ultrafiltration performances of the CA and CA-2,3-DA membranes. 
solutions. The water flux of the CA-2,3-DA membrane was $167.3 \mathrm{~L} \mathrm{~m}^{-2} \mathrm{~h}^{-1}$, which was about 2.2 times that of the CA membrane $\left(76.1 \mathrm{~L} \mathrm{~m}^{-2} \mathrm{~h}^{-1}\right)$. One possible explanation for the substantial increase in water flux is that the membrane's improved porosity and average pore size, optimized microstructure morphology, and improved surface hydrophilicity jointly promote the penetration of water molecules [28]. At the same time, concerning the BSA rejection ratio, both membranes showed excellent performance. Compared with the BSA rejection ratio of the CA membrane, $91.1 \%$, that of the CA-2,3-DA membrane was slightly increased to $92.5 \%$. In order to evaluate our work, the CA-based membranes were collected for comparison, and the comparison results are shown in Fig. 6. In contrast, the CA-2,3-DA membrane exhibited excellent comprehensive separation performance. In general, the CA-2,3-DA membrane maintained a high BSA rejection ratio while having a high water flux, which overcomes the long-term challenges of the trade-off between selectivity and permeability in traditional CA separation membranes to some extent.

\section{Antifouling properties of ultrafiltration membranes}

A three-cycle dynamic ultrafiltration experiment was carried out to evaluate the antifouling and recycling performances of the CA and CA-2,3-DA membranes,

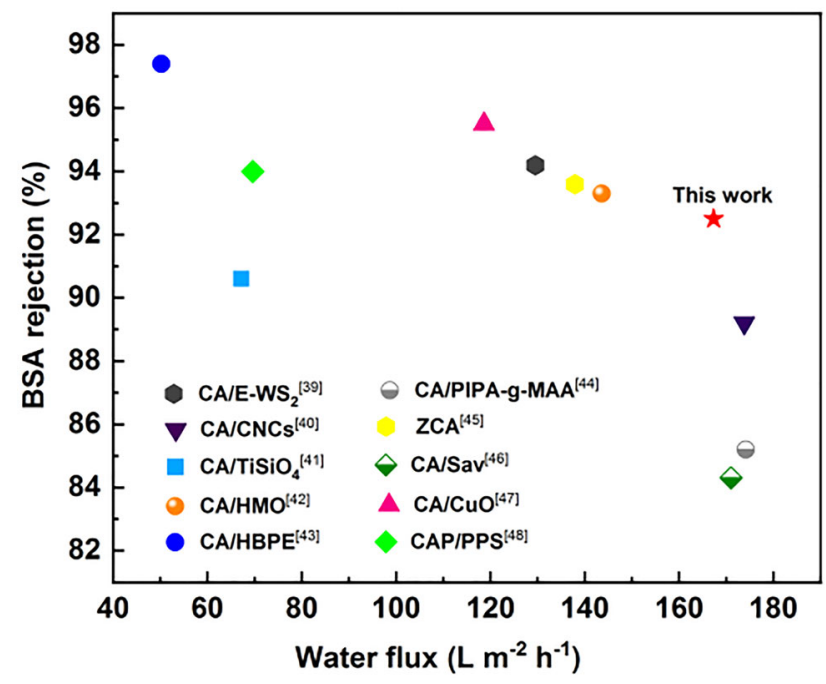

Figure 6 Comparison of BSA rejection and water flux of CAbased membranes reported in the literature [39-48] with CA-2,3DA membrane used in this work. and the relevant time-dependent flux curves are shown in Fig. 7 and the calculated data are summarized in Table 2. In the first cycle, after the BSA solution was filtered for $1 \mathrm{~h}$, the flux of both membranes showed a sharp decrease due to membrane fouling. After being cleaned, the CA-2,3-DA membrane showed a higher flux recovery ratio $(70.9 \%)$ than the CA membrane (64.6\%), indicating that the CA-2,3-DA membrane had better antifouling performance. Moreover, both membranes showed a trend of increasing rejection ratio and decreasing flux during the three-cycle. This is due to the adsorption and deposition of BSA molecules on the membrane surface and in the pores. And this fouling cannot be completely removed by simple physical washing. Therefore, to comprehensively monitor membrane fouling, three fouling parameters-total $\left(R_{\mathrm{t}}\right)$, reversible $\left(R_{\mathrm{r}}\right)$, and irreversible $\left(R_{\mathrm{ir}}\right)$ flux decline ratioswere calculated, and the results are shown in Fig. 8. It is worth noting that compared with the CA membrane, the CA-2,3-DA membrane had a significantly increased $R_{\mathrm{r}}$ based on a lower $R_{\mathrm{t}}$. This indicates that the fouling layer on the CA-2,3-DA membrane surface was loose and could be removed more easily by physical washing. However, the surface fouling of the CA membrane was controlled by irreversible fouling and could only be mitigated by chemical washing or biological degradation [31]. Consequently, the experimental results showed that the antifouling property of the CA membrane modified by dopamine was significantly improved, which is advantageous for its application.

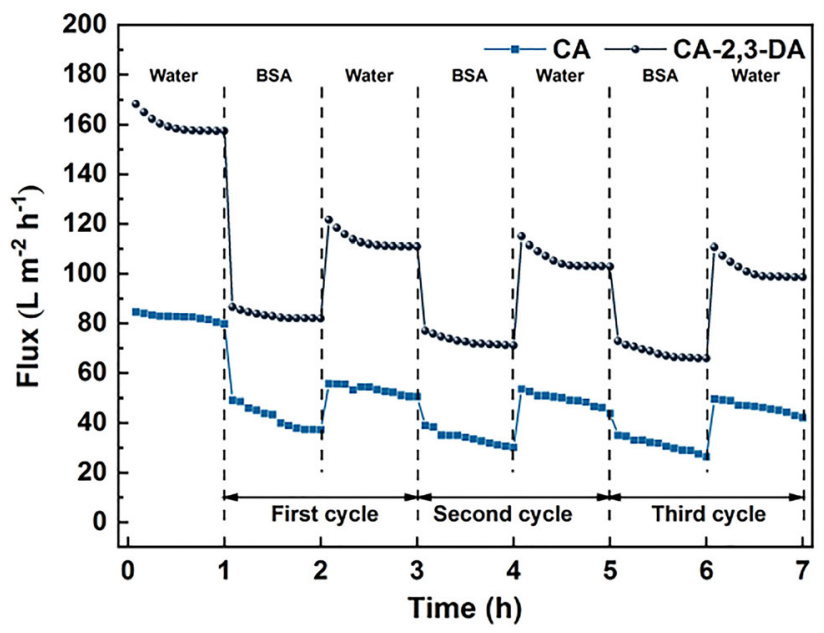

Figure 7 Time-dependent filtration fluxes of CA and CA-2,3-DA membranes during three-cycle protein ultrafiltration experiment. 
Table 2 Summary of pure water fluxes, protein permeation fluxes, and rejection ratios of the CA and CA-2,3-DA membranes

\begin{tabular}{|c|c|c|c|c|c|c|c|c|c|c|}
\hline \multirow[t]{2}{*}{ Membrane } & \multirow{2}{*}{$\begin{array}{l}J_{\mathrm{w} 0}(\mathrm{~L} \\
\left.\mathrm{m}^{-2} \mathrm{~h}^{-1}\right)\end{array}$} & \multicolumn{3}{|l|}{ First cycle } & \multicolumn{3}{|c|}{ Second cycle } & \multicolumn{3}{|c|}{ Third cycle } \\
\hline & & $\begin{array}{l}J_{\mathrm{p} 1}(\mathrm{~L} \\
\left.\mathrm{m}^{-2} \mathrm{~h}^{-1}\right)\end{array}$ & $\begin{array}{l}J_{\mathrm{w} 1}(\mathrm{~L} \\
\left.\mathrm{m}^{-2} \mathrm{~h}^{-1}\right)\end{array}$ & $\begin{array}{l}R_{1} \\
(\%)\end{array}$ & $\begin{array}{l}J_{\mathrm{p} 2}(\mathrm{~L} \\
\left.\mathrm{m}^{-2} \mathrm{~h}^{-1}\right)\end{array}$ & $\begin{array}{l}J_{\mathrm{w} 2}(\mathrm{~L} \\
\left.\mathrm{m}^{-2} \mathrm{~h}^{-1}\right)\end{array}$ & $\begin{array}{l}R_{2} \\
(\%)\end{array}$ & $\begin{array}{l}J_{\mathrm{p} 3}(\mathrm{~L} \\
\left.\mathrm{m}^{-2} \mathrm{~h}^{-1}\right)\end{array}$ & $\begin{array}{l}J_{\mathrm{w} 3}(\mathrm{~L} \\
\left.\mathrm{m}^{-2} \mathrm{~h}^{-1}\right)\end{array}$ & $\begin{array}{l}R_{3} \\
(\%)\end{array}$ \\
\hline $\mathrm{CA}$ & 79.8 & 37.3 & 50.5 & 92.5 & 30.2 & 43.9 & 94.3 & 65.8 & 98.6 & 96.3 \\
\hline $\begin{array}{c}\text { CA-2,3- } \\
\text { DA }\end{array}$ & 157.38 & 82.0 & 110.9 & 91.1 & 71.1 & 102.9 & 92.9 & 26.4 & 42.2 & 94.7 \\
\hline
\end{tabular}

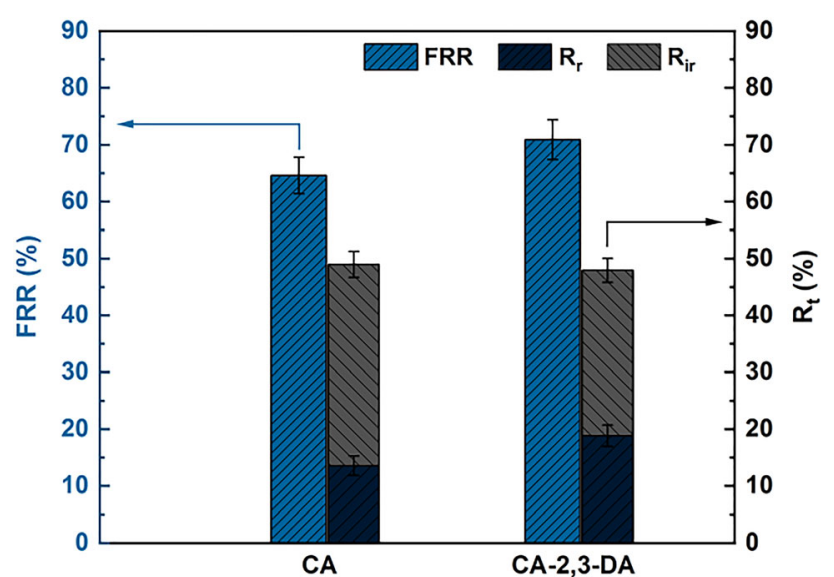

Figure 8 Flux recovery ratio $(F R R)$, total flux decline ratio $\left(R_{\mathrm{t}}=R_{\mathrm{r}}+R_{\mathrm{ir}}\right)$, reversible flux decline ratio $\left(R_{\mathrm{r}}\right)$, and irreversible flux decline ratio $\left(R_{\text {ir }}\right)$ of the $\mathrm{CA}$ and CA-2,3-DA membranes during protein ultrafiltration experiments.

Through the calculation of filtration resistance, the antifouling performance of the membrane can be

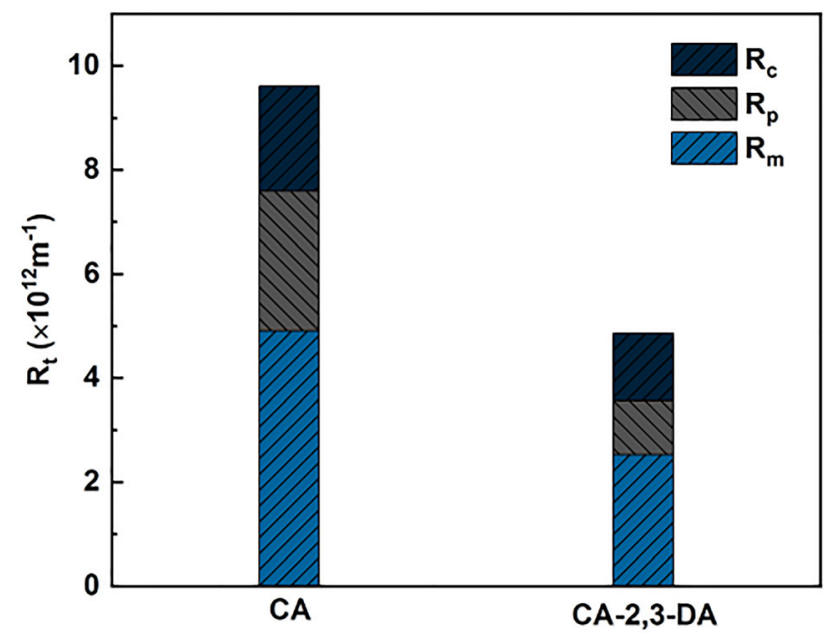

Figure 9 Total hydraulic resistance $\left(R_{\mathrm{t}}\right)$, membrane resistance $\left(R_{\mathrm{m}}\right)$, fouling resistance $\left(R_{\mathrm{f}}=R_{\mathrm{c}}+R_{\mathrm{p}}\right)$, cake layer resistance $\left(R_{\mathrm{c}}\right)$, and pore-blocking resistance $\left(R_{\mathrm{p}}\right)$ of CA and CA-2,3-DA membranes during cycles of the protein ultrafiltration experiment. more objectively evaluated. As shown in Fig. 9, the total hydraulic resistance of the CA membrane was 2.1 times that of the CA-2,3-DA membrane, which was almost consistent with the relationship between the pure water fluxes of the two membranes. The $R_{\mathrm{m}}$ value of the CA membrane was about 1.9 times that of the CA-2,3-DA membrane, which might be related to the intrinsic properties, lower porosity, and average pore size of the CA membrane. In addition, the $R_{\mathrm{f}}$ value of the CA membrane was 2.0 times that of the CA-2,3-DA membrane, indicating a higher degree of fouling. More importantly, for the CA-2,3-DA membrane, $R_{\mathrm{c}}$ accounted for $55.4 \%$ of $R_{\mathrm{f}}$, which means membrane fouling was dominated by reversible fouling. It was further proved that the introduction of dopamine could improve the antifouling performance of the CA membrane.

Figure 10 shows the flux recovery ratios of two prepared membranes after different cycles of the protein ultrafiltration experiment. In the first cycle,

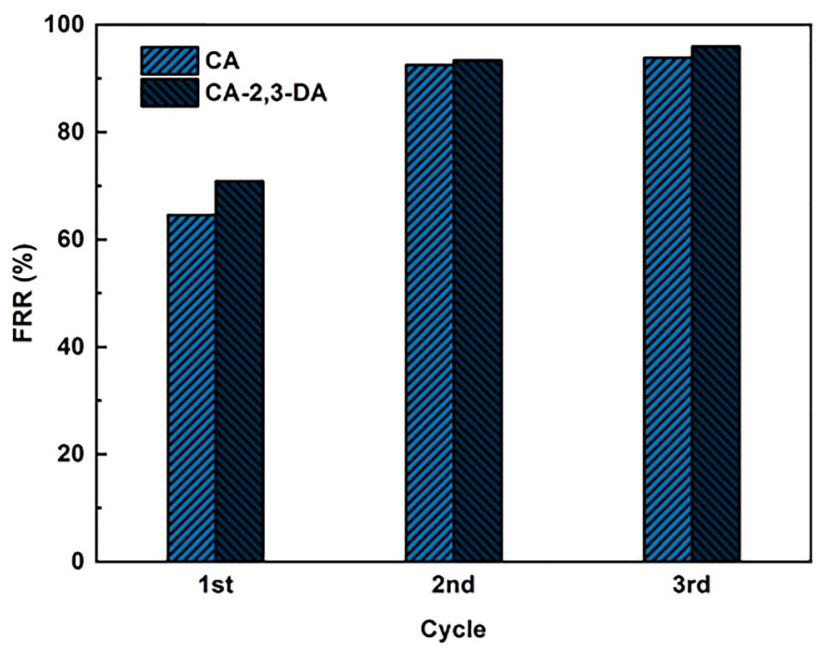

Figure 10 Flux recovery ratios $(F R R)$ of CA and CA-2,3-DA membranes after various cycles of protein ultrafiltration experiment. 
both membranes showed relatively low FRR values, $64.6 \%$ for CA and $70.9 \%$ for CA-2,3-DA, which were caused by membrane fouling. In the following two cycles, the FRR values of both membranes tended to stabilize at a higher level; in particular, the value of the CA-2,3-DA membrane was as high as $96.0 \%$ in the third cycle. Also, after three cycles of ultrafiltration, the pure water and BSA fluxes of the CA-2,3-DA membrane were as high as $101.6 \mathrm{~L} \mathrm{~m}^{-2} \mathrm{~h}^{-1}$ and 68.2 $\mathrm{L} \mathrm{m}^{-2} \mathrm{~h}^{-1}$, more than 2 times higher than those of the CA membrane. The above experimental results proved that the CA-2,3-DA membrane had outstanding antifouling property and long-term performance stability.

\section{Conclusion}

The problem of membrane fouling has largely restricted the development and application of ultrafiltration technology. Therefore, a scalable method to produce antifouling membranes by the traditional immersion precipitation phase inversion process is proposed, using a specially designed and prepared dopamine-modified cellulose acetate (CA-2,3-DA) based on selective oxidation and Schiff base reactions as the membrane material. In comparison to the pristine CA membrane, the CA-2,3-DA membrane maintained a higher rejection ratio for BSA $(92.5 \%)$ and had a greatly increased pure water flux $\left(167.3 \mathrm{~L} \mathrm{~m}^{-2} \mathrm{~h}^{-1}\right)$. In addition, the experimental results of static protein adsorption and dynamic cycle ultrafiltration showed that the CA-2,3-DA membrane had excellent antifouling performance and high recyclability, which were supported from different angles by parameters such as the high flux recovery ratio, low flux decline ratio, and filtration resistance. Even after three cycles of ultrafiltration, the water flux recovery ratio of CA-2,3-DA membrane was still maintained at $96.0 \%$. Consequently, CA-2,3-DA is expected to be widely used in various industrial separation and purification applications, thus realizing the extensive and high-value-added utilization of cellulose derivative materials.

\section{Acknowledgements}

We are thankful for the financial support from the Fundamental Research Funds for the Central
Universities (2572021BB07), Natural Science Foundation of Heilongjiang Province (LH2021B003), and Postdoctoral Scientific Research Developmental Fund of Heilongjiang Province (LBH-Q18005), China.

\section{References}

[1] Kaur S, Sundarrajan S, Rana D, Sridhar R, Gopal R, Matsuura T, Ramakrishna S (2014) Review: the characterization of electrospun nanofibrous liquid filtration membranes. J Mater Sci 49(18):6143-6159. https://doi.org/10.1007/s10 853-014-8308-y

[2] Liu Q, Chen Z, Pei X, Guo C, Teng K, Hu Y, Xu Z, Qian X (2019) Review: applications, effects and the prospects for electrospun nanofibrous mats in membrane separation. J Mater Sci 55(3):893-924. https://doi.org/10.1007/s10853019-04012-7

[3] Shi Y, Li C, He D, Shen L, Bao N (2017) Preparation of graphene oxide-cellulose acetate nanocomposite membrane for high-flux desalination. J Mater Sci 52(22):13296-13306. https://doi.org/10.1007/s10853-017-1403-0

[4] Liu SX, Kim J (2011) Characterization of surface modification of polyethersulfone membrane. J Adhes Sci Technol 25:193-212. https://doi.org/10.1163/016942410X503311

[5] Wang M, Xu ZW, Guo YL, Hou YF, Li P, Niu QJ (2020) Engineering a superwettable polyolefin membrane for highly efficient oil/water separation with excellent self-cleaning and photo-catalysis degradation property. J Membr Sci 611:118409. https://doi.org/10.1016/j.memsci.2020.118409

[6] Yu S, Kang GD, Zhu ZH, Zhou MQ, Yu HJ, Gao YM (2021) Nafion-PTFE hollow fiber composite membranes for improvement of anti-fouling and anti-wetting properties in vacuum membrane distillation. J Membr Sci 620:118915. h ttps://doi.org/10.1016/j.memsci.2020.118915

[7] Zhang Y, Fu Q (2018) Algal fouling of microfiltration and ultrafiltration membranes and control strategies: a review. Sep Purif Technol 203:193-208. https://doi.org/10.1016/j.se ppur.2018.04.040

[8] Wang C, Li Z, Chen J, Zhong Y, Ren L, Pu Y, Dong Z, Wu H (2018) Influence of blending zwitterionic functionalized titanium nanotubes on flux and anti-fouling performance of polyamide nanofiltration membranes. $J$ Mater Sci 53(14):10499-10512. https://doi.org/10.1007/s10853-018-2 288-2

[9] Zhu LJ, Liu F, Yu XM, Xue LX (2015) Poly (lactic acid) hemodialysis membranes with poly (lactic acid)-block-poly (2-hydroxyethyl methacrylate) copolymer as additive: preparation, characterization, and performance. ACS Appl 
Mater Interfaces 7:17748-17755. https://doi.org/10.1021/ac sami.5b03951

[10] Yang J, Zhang ZZ, Xu XH, Zhu XT, Men XH, Zhou XY (2012) Superhydrophilic-superoleophobic coatings. J Mater Chem 22:2834-2837. https://doi.org/10.1039/c2jm15987b

[11] Liu CH, Lee J, Ma J, Elimelech M (2017) Antifouling thinfilm composite membranes by controlled architecture of zwitterionic polymer brush layer. Environ Sci Technol 51:2161-2169. https://doi.org/10.1021/acs.est.6b05992

[12] Keating JJ, Imbrogno J, Belfort G (2016) Polymer brushes for membrane separations: a review. ACS Appl Mater Interfaces 8:28383-28399. https://doi.org/10.1021/acsami.6 b09068

[13] Liu MY, Zeng GJ, Wang K, Wan Q, Tao L, Zhang XY, Wei $Y$ (2016) Recent developments in polydopamine: an emerging soft matter for surface modification and biomedical applications. Nanoscale 8:16819-16840. https://doi.org/10. 1039/c5nr09078d

[14] Tian HL, Wu X, Zhang KS (2021) Polydopamine-assisted two-dimensional molybdenum disulfide (MoS2)-modified PES tight ultrafiltration mixed-matrix membranes: enhanced dye separation performance. Membranes 11:96. https://doi. org/10.3390/membranes11020096

[15] Mu YF, Feng H, Zhang SL, Zhang CY, Lu N, Luan JS, Wang GB (2020) Development of highly permeable and antifouling ultrafiltration membranes based on the synergistic effect of carboxylated polysulfone and bio-inspired co-deposition modified hydroxyapatite nanotubes. J Colloid Interface Sci 572:48-61. https://doi.org/10.1016/j.jcis.2020.03.072

[16] Kallem P, Ibrahim Y, Hasan SW, Show PL, Banat F (2021) Fabrication of novel polyethersulfone (PES) hybrid ultrafiltration membranes with superior permeability and antifouling properties using environmentally friendly sulfonated functionalized polydopamine nanofillers. Sep Purif Technol 261:118311. https://doi.org/10.1016/j.seppur.2021.118311

[17] Fei F, Le Phuong H, Blanford C, Szekely G (2019) Tailoring the performance of organic solvent nanofiltration membranes with biophenol coatings. ACS Appl Polym Mater 1(3):452-460. https://doi.org/10.1021/acsapm.8b00161

[18] Shen J, Zhang R, Su Y, Shi B, You X, Guo W, Ma Y, Yuan J, Wang F, Jiang Z (2019) Polydopamine-modulated covalent organic framework membranes for molecular separation. J Mater Chem A 7(30):18063-18071. https://doi.org/10.10 39/c9ta05040j

[19] Li Y, Shi S, Cao H, Xu B, Zhao Z, Cao R, Chang J, Duan F, Wen $H$ (2020) Anion exchange nanocomposite membranes modified with graphene oxide and polydopamine: interfacial structure and antifouling applications. ACS Appl Nano Mater 3(1):588-596. https://doi.org/10.1021/acsanm.9b 02142
[20] Alammar A, Park S, Williams C, Derby B, Szekely G (2020) Oil-in-water separation with graphene-based nanocomposite membranes for produced water treatment. J Membr Sci 603:118007. https://doi.org/10.1016/j.memsci.2020.118007

[21] Choi YS, Kang H, Kim DG, Cha SH, Lee JC (2014) Musselinspired dopamine-and plant-based cardanol-containing polymer coatings for multifunctional filtration membranes. ACS Appl Mater Interfaces 6:21297-21307. https://doi.org/ 10.1021/am506263s

[22] Chen XY, Deng ED, Park D, Pfeifer BA, Dai N, Lin HQ (2020) Grafting activated graphene oxide nanosheets onto ultrafiltration membranes using polydopamine to enhance antifouling properties. ACS Appl Mater Interfaces 12:48179-48187. https://doi.org/10.1021/acsami.0c14210

[23] Li RJ, Li JY, Rao LH, Lin HJ, Shen LG, Xu YC, Chen JR, Liao BQ (2021) Inkjet printing of dopamine followed by UV light irradiation to modify mussel-inspired PVDF membrane for efficient oil-water separation. J Membr Sci 619:118790. h ttps://doi.org/10.1016/j.memsci.2020.118790

[24] Xie WC, Li T, Tiraferri A, Drioli E, Figoli A, Crittenden JC, Liu BC (2021) Toward the next generation of sustainable membranes from green chemistry principles. ACS Sustain Chem Eng 9:50-75. https://doi.org/10.1021/acssuschemeng. 0c07119

[25] Rafieian F, Mousavi M, Dufresne A, Yu QL (2020) Polyethersulfone membrane embedded with amine functionalized microcrystalline cellulose. Int J Biol Macromol 164:4444-4454. https://doi.org/10.1016/j.ijbiomac.2020.09. 017

[26] Zhou L, Ke K, Yang MB, Yang W (2021) Recent progress on chemical modification of cellulose for high mechanicalperformance poly (lactic acid)/cellulose composite: a review. Compos Commun 23:100548. https://doi.org/10.1016/j.coc 0.2020 .100548

[27] Silva MA, Belmonte-Reche E, Amorim MTP (2021) Morphology and water flux of produced cellulose acetate membranes reinforced by the design of experiments (DOE). Carbohydr Polym 254:117407. https://doi.org/10.1016/j.carb pol.2020.117407

[28] Guo HX, Peng Y, Liu Y, Wang ZF, Hu JW, Liu JH, Ding Q, $\mathrm{Gu}$ JY (2020) Development and investigation of novel antifouling cellulose acetate ultrafiltration membrane based on dopamine modification. Int $\mathrm{J}$ Biol Macromol 160:652-659. https://doi.org/10.1016/j.ijbiomac.2020.05. 223

[29] Huang HT, Yu JY, Guo HX, Shen YB, Yang F, Wang H, Liu R, Liu Y (2018) Improved antifouling performance of ultrafiltration membrane via preparing novel zwitterionic polyimide. Appl Surf Sci 427:38-47. https://doi.org/10.101 6/j.apsusc.2017.08.004 
[30] Wang ZF, Chen PY, Liu Y, Guo HX, Sun N, Cai QQ, Yu YY, Zhao FB (2021) Exploration of antifouling zwitterionic polyimide ultrafiltration membrane based on novel aromatic diamine monomer. Sep Purif Technol 255:117738. https://d oi.org/10.1016/j.seppur.2020.117738

[31] Guo HX, Wang ZF, Liu Y, Huo PF, Gu JY, Zhao FB (2020) Synthesis and characterization of novel zwitterionic poly (aryl ether oxadiazole) ultrafiltration membrane with good antifouling and antibacterial properties. J Membr Sci 611:118337. https://doi.org/10.1016/j.cclet.2007.11.005

[32] Yu Q, Qin Y, Han MY, Pan F, Han L, Yin XZ, Chen ZM, Wang LX, Wang H (2020) Preparation and characterization of solvent-free fluids reinforced and plasticized polylactic acid fibrous membrane. Int J Biol Macromol 161:122-131. h ttps://doi.org/10.1016/j.ijbiomac.2020.06.027

[33] Zhang LM, Zhang Q, Zheng YQ, He ZN, Guan P, He XH, Hui LF, Dai YJ (2018) Study of Schiff base formation between dialdehyde cellulose and proteins, and its application for the deproteinization of crude polysaccharide extracts. Ind Crops Prod 112:532-540. https://doi.org/10.10 16/j.indcrop.2017.12.056

[34] Li K, Jin SC, Chen H, Li JZ (2019) Bioinspired interface engineering of gelatin/cellulose nanofibrils nanocomposites with high mechanical performance and antibacterial properties for active packaging. Compos B 171:222-234. http s://doi.org/10.1016/j.compositesb.2019.04.043

[35] Guo TY, Gu LH, Zhang Y, Chen H, Jiang B, Zhao HF, Jin YC, Xiao HN (2019) Bioinspired self-assembled films of carboxymethyl cellulose-dopamine/montmorillonite. J Mater Chem A 7:14033-14041. https://doi.org/10.1039/ C9TA00998A

[36] Zhong YJ, Wang J, Yuan ZY, Wang Y, Xi ZH, Li L, Liu ZY, Guo XH (2019) A mussel-inspired carboxymethyl cellulose hydrogel with enhanced adhesiveness through enzymatic crosslinking. Colloids Surf B 179:462-469. https://doi.org/ 10.1016/j.colsurfb.2019.03.044

[37] Khamrai M, Banerjee SL, Pau S, Ghosh AK, Sarkar P, Kundu PP (2019) A mussel mimetic, bioadhesive, antimicrobial patch based on dopamine-modified bacterial cellulose/rGO/Ag NPs: a green approach toward wound-healing applications. ACS Sustain Chem Eng 51(4):12083-12097. h ttps://doi.org/10.1021/acssuschemeng.9b01163

[38] Wu J, Chen SF (2012) Investigation of the hydration of nonfouling material poly (ethylene glycol) by low-field nuclear magnetic resonance. Langmuir 28:2137-2144. http s://doi.org/10.1021/la203827h

[39] Vetrivel S, Sri Abirami Saraswathi M, Rana D, Divya K, Nagendran A (2018) Cellulose acetate composite membranes tailored with exfoliated tungsten disulfide nanosheets: permeation characteristics and antifouling ability. Int J Biol Macromol 115:540-546. https://doi.org/10.10 16/j.ijbiomac.2018.04.091

[40] Lv JL, Zhang GQ, Zhang HM, Yang FL (2017) Exploration of permeability and antifouling performance on modified cellulose acetate ultrafiltration membrane with cellulose nanocrystals. Carbohydr Polym 174:190-199. https://doi.or g/10.1016/j.carbpol.2017.06.064

[41] Dasgupta J, Chakraborty S, Sikder J, Kumar R, Pal D, Curcio S, Drioli E (2014) The effects of thermally stable titanium silicon oxide nanoparticles on structure and performance of cellulose acetate ultrafiltration membranes. Sep Purif Technol 133:55-68. https://doi.org/10.1016/j.seppur.2 014.06.035

[42] Vetrivel S, Rana D, Sri Abirami Saraswathi MS, Divya K, Kaleekkal NJ, Nagendran A (2019) Cellulose acetate nanocomposite ultrafiltration membranes tailored with hydrous manganese dioxide nanoparticles for water treatment applications. Polym Adv Technol 30:1943-1950. http s://doi.org/10.1002/pat.4626

[43] Mahdavi H, Shahalizade T (2015) Preparation, characterization and performance study of cellulose acetate membranes modified by aliphatic hyperbranched polyester. J Membr Sci 473:256-266. https://doi.org/10.1016/j.memsc i.2014.09.013

[44] Jayalakshmi A, Rajesh S, Kim IC, Senthilkumar S, Mohan D, Kwon YN (2014) Poly(isophthalamide) based graft copolymer for the modification of cellulose acetate ultrafiltration membranes and a fouling study by AFM imaging. J Membr Sci 465:117-128. https://doi.org/10.1016/j.memsci. 2014.04.020

[45] Liu Y, Huang HT, Huo PF, Gu JY (2017) Exploration of zwitterionic cellulose acetate antifouling ultrafiltration membrane for bovine serum albumin (BSA) separation. Carbohydr Polym 165:266-275. https://doi.org/10.1016/j.ca rbpol.2017.02.052

[46] Koseoglu-Imer DY, Dizge N, Koyuncu I (2012) Enzymatic activation of cellulose acetate membrane for reducing of protein fouling. Colloids Surf B 92:334-339. https://doi.org/ 10.1016/j.colsurfb.2011.12.013

[47] Vetrivel S, Saraswathi MSSA, Rana D, Divya K, Nagendran A (2020) Cellulose acetate ultrafiltration membranes customized with copper oxide nanoparticles for efficient separation with antifouling behavior. J Appl Polym Sci 138:49867. https://doi.org/10.1002/app.49867

[48] Kumar M, RaoT S, Isloor AM, Ibrahim GPS, Ismail N, Ismail AF, Asiri AM (2019) Use of cellulose acetate/ 
polyphenylsulfone derivatives to fabricate ultrafiltration hollow fiber membranes for the removal of arsenic from drinking water. Int J Biol Macromol 129:715-727. https://d oi.org/10.1016/j.ijbiomac.2019.02.017
Publisher's Note Springer Nature remains neutral with regard to jurisdictional claims in published maps and institutional affiliations. 